\title{
Decomposition of regional wage differences along the wage distribution in Portugal: the importance of covariates
}

\author{
Aurora Galego, João Pereira \\ Department of Economics and CEFAGE-UE, University of Évora, Largo dos Colegiais, 2, \\ 7000-803 Évora, Portugal; email: agalego@uevora.pt,jpereira@uevora.pt \\ Received 19 June 2013; in revised form 9 April 2014
}

\begin{abstract}
Unlike previous studies, in this paper we estimate the contribution of covariates for the regional wage decomposition components along the wage distribution employing a method first described in 2009 by S Firpo, N Fortin, and T Lemieu (Econometrica 77 953-973). We consider the case of Portugal, a country with persistent and large regional wage gaps. We find that education, occupation, and firm size are the most important factors in explaining the growing importance of the composition effect. The wage structure effect, in turn, is mainly determined by differences in reward for experience and tenure. Moreover, we conclude that the importance of these covariates for both effects is not equal along the wage distribution.
\end{abstract}

Keywords: regions, wage differentials, wage decompositions, unconditional quantile regression, recentred influence function

\section{Introduction}

Regional wage gaps are known to be important in many countries (Blackaby and Manning, 1990; García and Molina, 2002; Pereira and Galego, 2011). Therefore, governments often have specific policies targeted at regions that lag behind structurally. These policies require a comprehensive understanding of the causes of the regional wage differences, which should be based on solid theoretical and empirical knowledge.

The economic literature has put forward several explanations for the existence of spatial wage differentials. ${ }^{(1)}$ For example, in the classical paradigm of the competitive economy, price (wage) differentials may arise if there are substantial differences in amenities, such as extreme climatic conditions or pollution (Roback, 1982). Yet, regional gaps may also exist as a consequence of temporary disequilibrium situations (Blackaby and Manning, 1990) or external economies, due to human capital (Glaeser et al, 1992; Lucas, 1988) or to industrial concentration in cities or regions (Marshall, 1890; Porter, 1990; Romer, 1986).

Another branch of the literature emphasizes the fact that workers in urban areas earn more than their nonurban counterparts (Addario and Patacchini, 2008; Glaeser and Maré, 2001; Yankow, 2006). This may be the result of cost of living differences; ability sorting effects (Fuchs, 1967; Yankow, 2006); external economies (Addario and Pataccini, 2008); or more efficient and productive matches between workers and firms (Combes et al, 2008; Wheeler, 2001). More recently, the new economic geography literature (see, for example, Fujita et al, 1999; Krugman, 1991) suggests mechanisms of nominal (but not real) regional wage differentials. They predict that nominal wages will be higher in regions that have easy access to economic centres due to the stronger demand linkages in these regions.

${ }^{(1)}$ A detailed presentation of these theoretical explanations can be seen in Pereira and Galego (2011) or Pereira and Galego (2014). 